\title{
TEM Study on Stability of Mg-Doped $\gamma$-Alumina Fine Particles
}

\author{
Michiko Kusunoki, Masumi Rokkaku ${ }^{\dagger}$, Yuichi Ikuhara ${ }^{\dagger \dagger}$ \\ and Hiroaki Yanagida
}

Japan Fine Ceramics Center 2-4-1 Mutsuno, Atsuta-ku, Nagoya 456, Japan

\begin{abstract}
Ultrafine spherical particles of $\gamma-\mathrm{Al}_{2} \mathrm{O}_{3}$ containing 4 at $\%$ magnesium and pure $\gamma-\mathrm{Al}_{2} \mathrm{O}_{3}$ were prepared by evaporating metal $\mathrm{Al}$ in air. Consequently, both particles were heated at $1400^{\circ} \mathrm{C}$ for $6 \mathrm{~h}$ in a vacuum. TEM observations showed that the $\mathrm{Mg}$-doped $\gamma-\mathrm{Al}_{2} \mathrm{O}_{3}$ particles were much more stable than the pure $\gamma-\mathrm{Al}_{2} \mathrm{O}_{3}$ particles. The role of $\mathrm{Mg}$ atoms on the stability is discussed mainly based on the results obtained by high-resolution electron microscopy and energy dispersive X-ray spectroscopy.
\end{abstract}

(Received July 25, 1997)

Keywords: $\gamma-\mathrm{Al}_{2} \mathrm{O}_{3}$, magnesium, spinel, transmission electron microscopy, high-resolution electron microscopy, phase transformation, thermal stability

\section{Introduction}

Recently, the necessity for a large-surface-area and thermally stable support material is increasingly called for catalytic combustion above $1000^{\circ} \mathrm{C}$. Commercial $\gamma$ $\mathrm{Al}_{2} \mathrm{O}_{3}$ powder (a common designation for the metastable phases of alumina) has been widely used as the support material for the purpose, however, sintering is hastened rapidly by the transformation of $\gamma-\mathrm{Al}_{2} \mathrm{O}_{3}$ to $\alpha-\mathrm{Al}_{2} \mathrm{O}_{3}$ at about $1100^{\circ} \mathrm{C}$. The addition of the rare earth such as $\mathrm{La}_{2} \mathrm{O}_{3}$ was reported to effectively increase the thermal stability of $\gamma-\mathrm{Al}_{2} \mathrm{O}_{3}{ }^{(1)(2)}$. In this case, the surface layers is considered to form of a compound with $\mathrm{Al}_{2} \mathrm{O}_{3}$ which hinders surface diffusion and nucleation of $\alpha-\mathrm{Al}_{2} \mathrm{O}_{3}$.

On the other hand, it is reported that the $\gamma-\mathrm{Al}_{2} \mathrm{O}_{3}$ preparede by the evaporation method has higher thermal stability than the commercial $\gamma-\mathrm{Al}_{2} \mathrm{O}_{3}{ }^{(3)(4)}$ which is generally produced by the dehydration of aluminum hydroxides. From the results, it was shown that the crystallinity affect the thermal stability of $\gamma-\mathrm{Al}_{2} \mathrm{O}_{3}$. The crystal structure and the grain boundary of $\gamma-\mathrm{Al}_{2} \mathrm{O}_{3}$ particles prepared by evaporation were investigated by high resolution electron microscopy (HREM) ${ }^{(5)(6)}$.

In this study, we investigate the stability of $\gamma-\mathrm{Al}_{2} \mathrm{O}_{3}$ powder containing $\mathrm{Mg}$ produced by an evaporating method and discuss the role of $\mathrm{Mg}$ on the basis of the microstructural examination by transmission electron microscopy.

$\dagger$ Graduate Student, Meijo University, Tenpaku-ku, Nagoya 468, Japan.

It Present address: Department of Materials Science, The University of Tokyo, Hongo, Bunkyo-ku, Tokyo 113, Japan.

\section{Experimental Procedure}

Figure 1 illustrates the preparation method of spherical $\gamma-\mathrm{Al}_{2} \mathrm{O}_{3}$ particles containing $\mathrm{Mg}$ by evaporating aluminum in air (sample A). An Al block ( $\phi 5 \mathrm{~mm} \times 10 \mathrm{~mm}$ ) on a porous alumina brick containing 0.6 mass $\% \mathrm{MgO}$ was burnt in a burner using a mixture of city gas (natural gas) and oxygen (the mixing ratio was about one to three). A thin white alumina shell was formed and the metal aluminum inside was melted. The melted aluminum then oozed out from a small crack in the alumina shell, and a white smoke consisting of $\mathrm{Al}_{2} \mathrm{O}_{3}$ powders was produced. The powder that rose as a smoke was collected by a metal mesh for TEM observation.

On the other hand, pure $\gamma-\mathrm{Al}_{2} \mathrm{O}_{3}$ powder was prepared by an evaporating method in which aluminum powder with a size of several micrometers floating by fuel gas

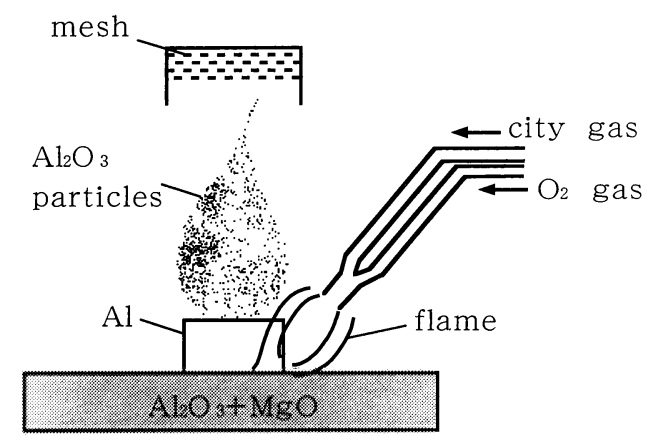

Fig. 1 Preparation of $\gamma-\mathrm{Al}_{2} \mathrm{O}_{3}$ powder containing 4 at $\% \mathrm{Mg}$. An $\mathrm{Al}$ block, was burnt in a burner using a mixture of city gas (natural gas) and oxygen gas on a porous alumina brick containing 0.6 mass $\%$ $\mathrm{MgO}$. 
$\left(\mathrm{H}_{2}+\mathrm{CH}_{4}\right)$ was burnt in a burner ${ }^{(4)}$ (sample B). Both powders of the samples $\mathrm{A}$ and $\mathrm{B}$ were mounted gently on a commercial pure amorphous carbon plate with a purity of $99.999 \%$ (Nippon Carbon Co. Ltd.), which had been cut to a size of $\phi 3 \mathrm{~mm} \times 0.1 \mathrm{~mm}$, and a small hole was made by dimpling on the center for TEM observation. Both the samples A and $\mathrm{B}$ were heated at $1400^{\circ} \mathrm{C}$ for $21600 \mathrm{~s}(6 \mathrm{~h})$ in a vacuum of about $1.3 \times 10^{-4} \mathrm{~Pa}$. The electron microscopes used in the present experiment were a JEOL-4000FX operating at $400 \mathrm{kV}$ and a Topcon-002B operating at $200 \mathrm{kV}$ for high-resolution observation. The structure of each $\mathrm{Al}_{2} \mathrm{O}_{3}$ ultrafine particle was determined by selected area electron diffraction and micro-diffraction methods. The chemical composition was analyzed by EDS and electron probe micro analysis (EPMA).

\section{Results and Discussion}

Figures 2(a) and (b) show the micrographs and the electron diffraction ring patterns of sample $\mathrm{A}$ and $\mathrm{B}$, respectively. The diameter of these particles was $20-150 \mathrm{~nm}$, and each particle was confirmed to be a single crystal of $\delta$ or $\theta-\mathrm{Al}_{2} \mathrm{O}_{3}$ by electron diffraction patterns. In the case of sample $\mathrm{A}$, an average amount of $\mathrm{Mg}$ was determined to be 4.0 at $\%$ by EPMA. EDS analyses were carried out to determine the composition of each particle for both sample A and B. Figures 3(a) and (b) are typical EDS profiles obtained from a particle in sample $\mathrm{A}$ and $\mathrm{B}$, respectively. In the sample $\mathrm{A}$, about 3-5 at\% amount of $\mathrm{Mg}$ was

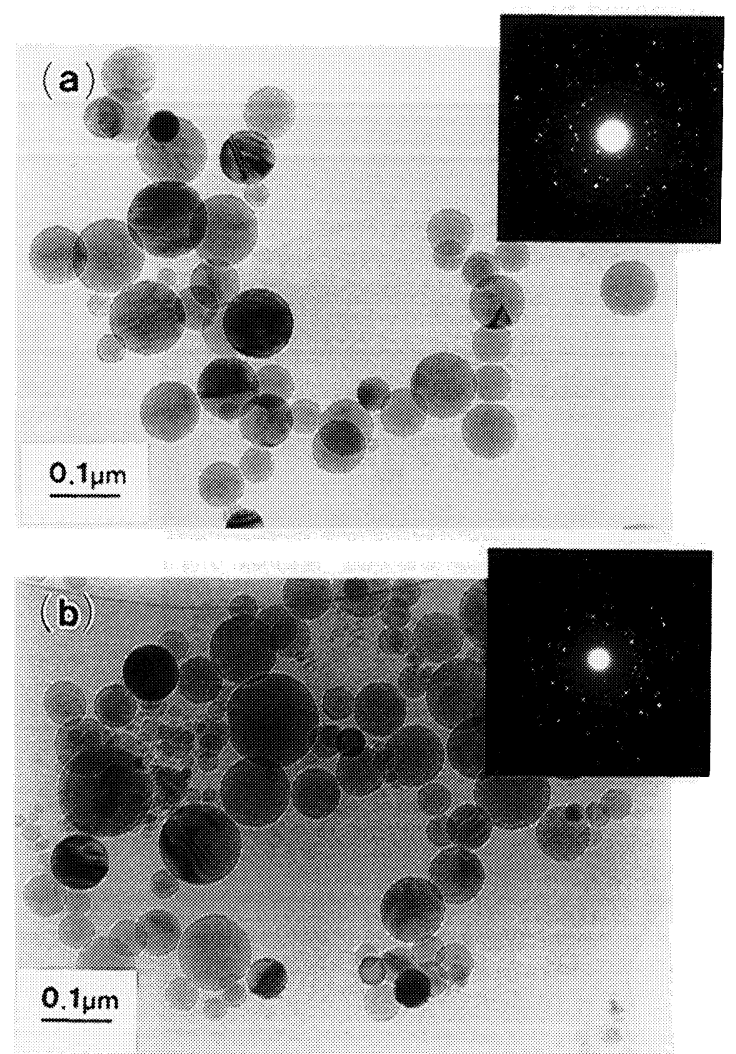

Fig. 2 TEM micrographs and the electron diffraction ring patterns of (a) sample A and (b) sample B. detected and no element other than $\mathrm{Al}, \mathrm{Mg}$, and $\mathrm{O}$ was found. In the sample $\mathrm{B}$, only the peaks of $\mathrm{Al}$ and $\mathrm{O}$ were detected. It is thus considered that the $\mathrm{Mg}$ atoms was evaporated from the slightly melted surface of the alumina brick containing $\mathrm{MgO}$ and diffused into $\mathrm{Al}_{2} \mathrm{O}_{3}$ particles.

Figures 4(a) and (b) are the micrographs and the electron diffraction patterns for the samples $\mathrm{A}$ and $\mathrm{B}$, respectively, heated at $1400^{\circ} \mathrm{C}$ for $6 \mathrm{~h}$ in a vacuum furnace. The particle size of the sample $A$ was almost the same as that before heating, as shown in Fig. 2(a), although the initial stage of sintering was observed, as shown by arrows. The ring pattern indicates that most of the particles are still consisted of $\gamma$-type $\mathrm{Al}_{2} \mathrm{O}_{3}$. In the sample $\mathrm{B}$, the particles grew to over $0.3 \mu \mathrm{m}$, as shown in Fig. 3 (b). Selected area diffraction patterns show that all of these particles were transformed to $\alpha-\mathrm{Al}_{2} \mathrm{O}_{3}$. The difference between Figs. 4(a) and (b) indicate that the $\mathrm{Mg}$ atoms in $\gamma-\mathrm{Al}_{2} \mathrm{O}_{3}$ remarkably improved the stability of the $\gamma$-phase and the restraint of grain growth.

Figure 5 shows a HREM image and the micro-diffraction patterns of the sample $\mathrm{A}$ heated at $1400^{\circ} \mathrm{C}$ for $6 \mathrm{~h}$. A neck was observed between two particles, one $\phi 54 \mathrm{~nm}$ in diameter, the other $\phi 62 \mathrm{~nm}$. The micro-diffraction patterns show that each is a single crystal of $\delta-\mathrm{Al}_{2} \mathrm{O}_{3}$. Although the (111) $y$-phase lattice planes of the two particles were aligned, grain growth was mostly restrained.

Figures 6(a), (b), (c) and (d) are the results of EDS obtained with a probe size of $\phi 4 \mathrm{~nm}$ from the area A, B, C and $\mathrm{D}$, shown in Fig. 5, respectively. In each point, only the peaks of $\mathrm{Al}, \mathrm{Mg}$ and $\mathrm{O}$ were detected. The ratios of
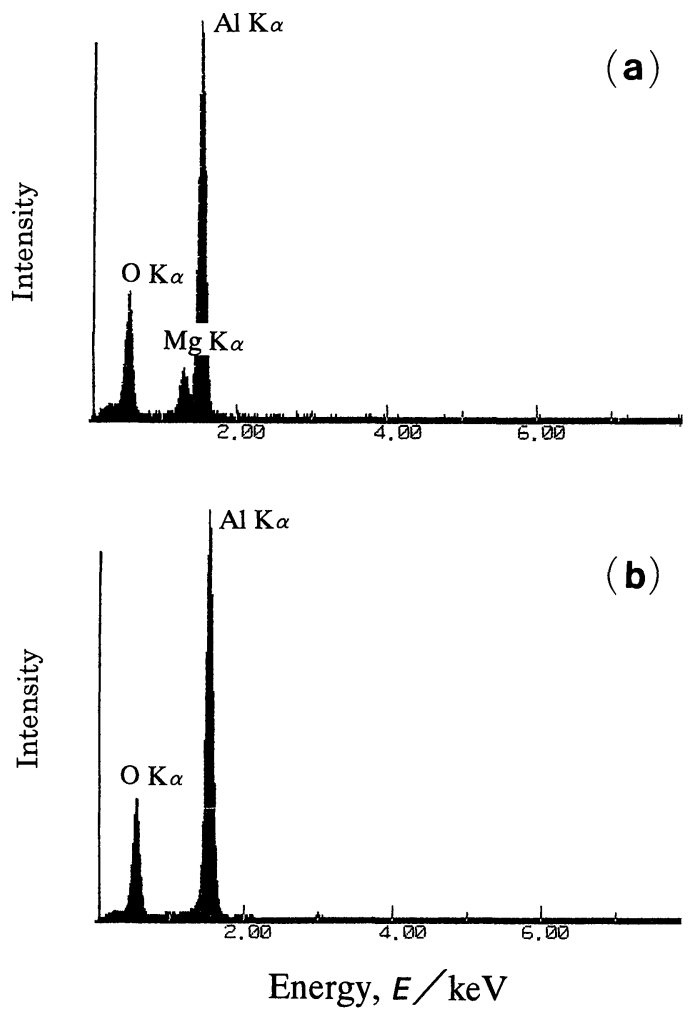

Fig. 3 EDS diagrams of (a) sample A and (b) sample B. 

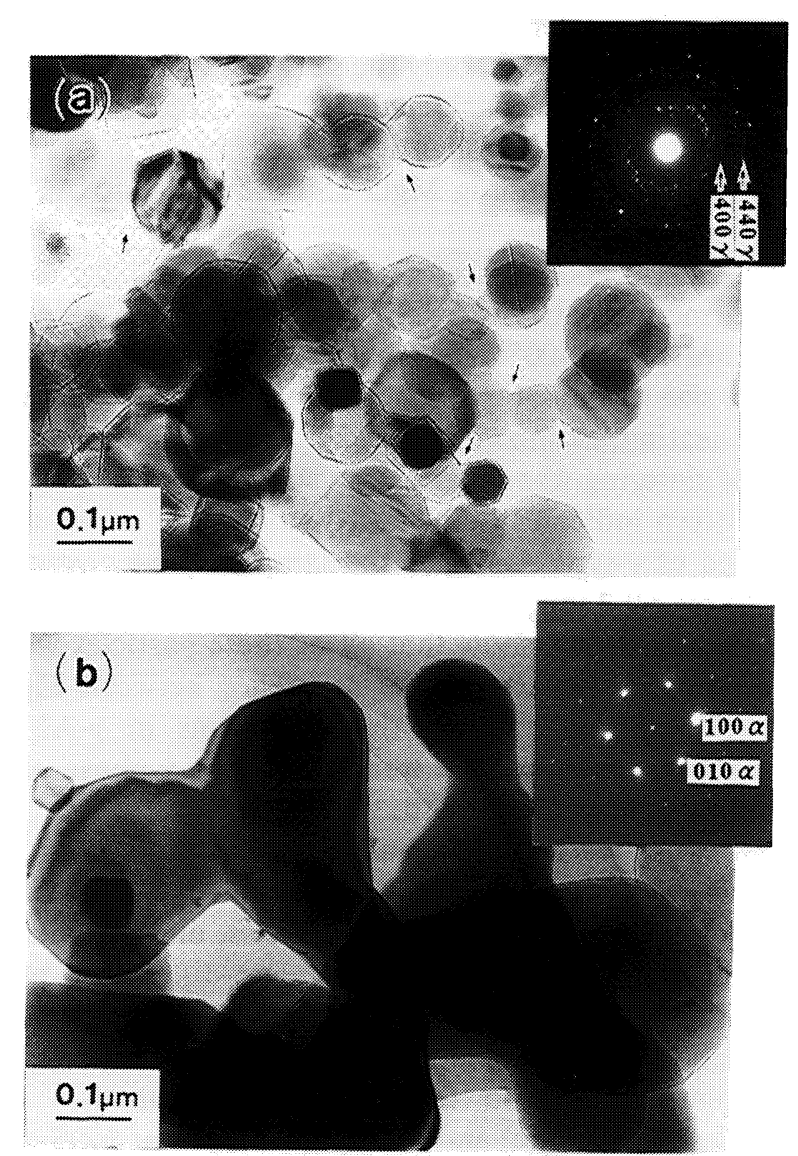

Fig. 4 TEM micrographs and the electron diffraction patterns of (a) sample A and (b) sample B heated at $1400^{\circ} \mathrm{C}$ for $21600 \mathrm{~s}(6 \mathrm{~h})$ in a vacuum furnace.
$\mathrm{Al}$ and $\mathrm{Mg}$ in the area $\mathrm{A}, \mathrm{B}, \mathrm{C}$ and $\mathrm{D}$ were almost the same within the range of the measurement error for EDS. Though five necks were selected randomly and their EDS diagrams were obtained, the results were the same. The results of the HREM image, the micro-diffraction patterns, and EDS show that $\mathrm{Mg}$ atoms were uniformly dissolved in $\gamma-\mathrm{Al}_{2} \mathrm{O}_{3}$ crystallographically and the restraint of sintering shown in Fig. 4(a) was not caused by segregation of $\mathrm{Mg}$ to the surfaces or the boundaries of the particles.

$\gamma-\mathrm{Al}_{2} \mathrm{O}_{3}$ is known to be constructed based on the spinel structure $\left(\mathrm{MgAl}_{2} \mathrm{O}_{4}\right)_{8} .8 \mathrm{Mg}$ atoms in tetrahedral sites are replaced with $5 \frac{1}{3} \mathrm{Al}$ atoms and, as the result, $1 / 9$ sites to the total metal sites of spinel structure are vacant in $\gamma-\mathrm{Al}_{2} \mathrm{O}_{3}$. From this fact and the experimental results, it is considered that $\mathrm{Mg}$ atoms doped in the $\gamma-\mathrm{Al}_{2} \mathrm{O}_{3}$ crystal by the evaporating method occupied preferentially a part of tetrahedral vacancy sites, and fcc-configuration of oxygen atoms of the spinel structure was stabilized.

Figure 7 shows a TEM micrograph and the selected area diffraction pattern of the sample A heated at $1500^{\circ} \mathrm{C}$ for $120 \mathrm{~h}$. The incident beam direction is parallel to $[010]_{\theta}$. It contains twin spots. It is found that sintering and grain growth progressed to a great extent, however, the structure was maintained to be $\theta-\mathrm{Al}_{2} \mathrm{O}_{3}$. This also indicates that $\mathrm{Mg}$ atoms doping was effective for the stabilization of spinel structure.

\section{Conclusions}

Thermally stable particles of $\gamma-\mathrm{Al}_{2} \mathrm{O}_{3}$ containing $\mathrm{Mg}$ were prepared by an evaporating method in air. The pow-

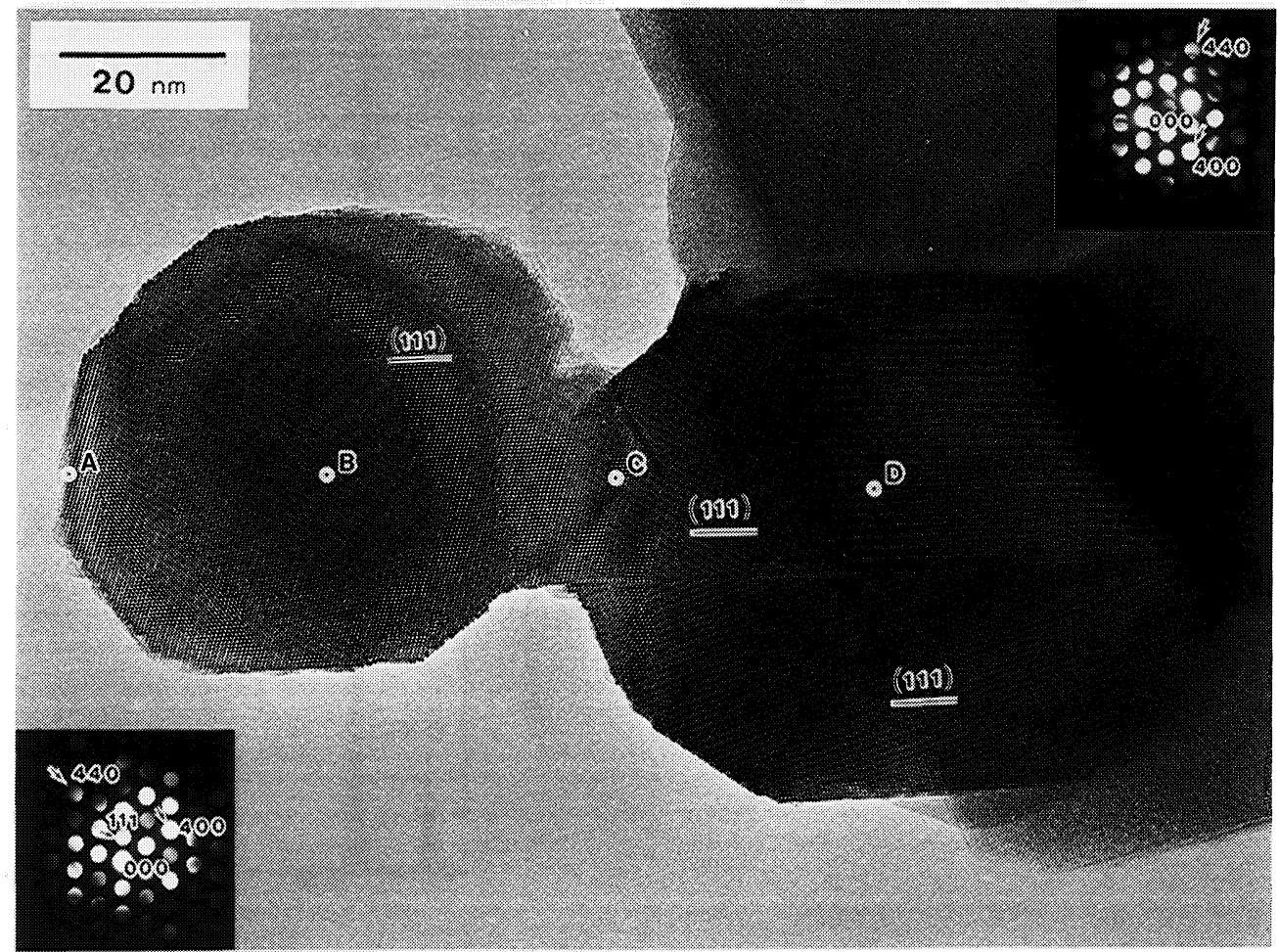

Fig. 5 HREM image and the micro-diffraction patterns of the particles of heated sample A at $1400^{\circ} \mathrm{C}$ for $21600 \mathrm{~s}(6 \mathrm{~h})$. 

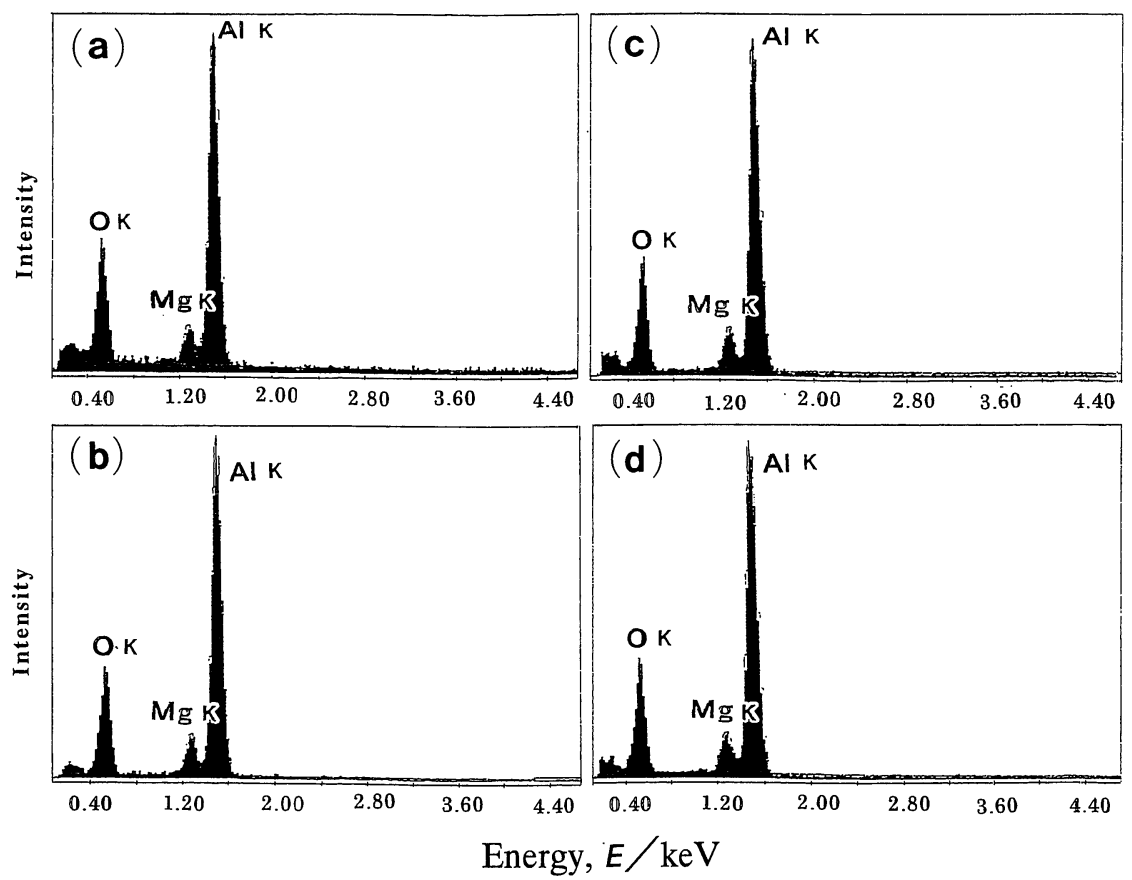

Fig. 6 (a), (b), (c) and (d): EDS diagrams of area A, B, C and D shown in Fig. 5, respectively. Each probe size was $\phi 4 \mathrm{~nm}$.

\section{$1500^{\circ} \mathrm{C}, 120 \mathrm{~h}$}

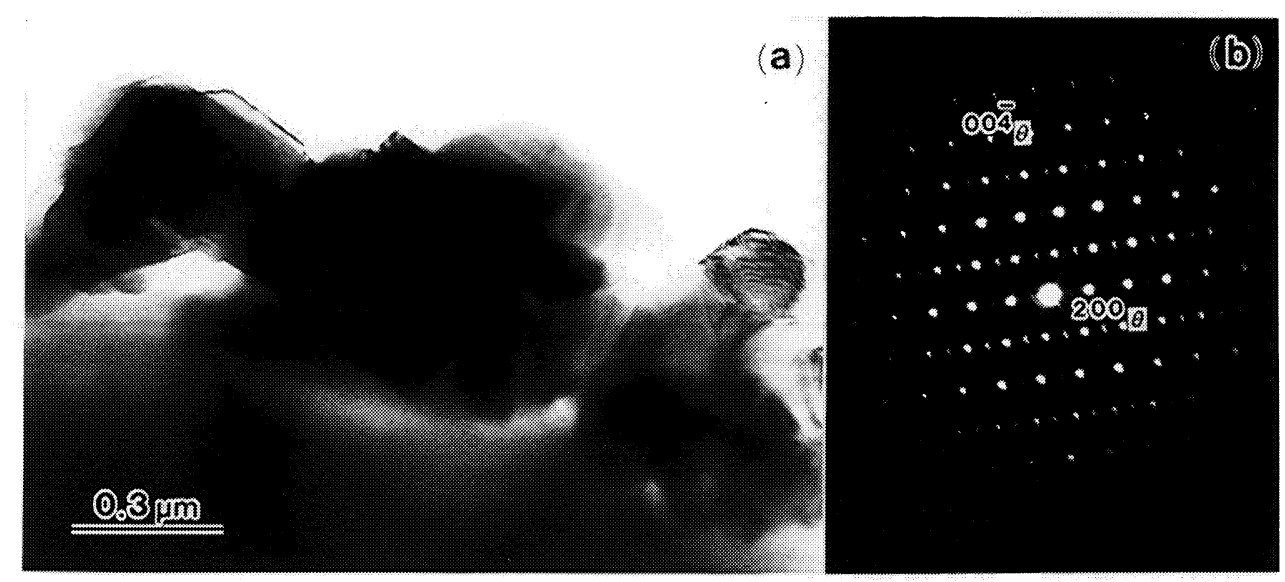

Fig. 7 (a) Electron micrograph of heated sample $\mathrm{A}$ at $1500^{\circ} \mathrm{C}$ for $120 \mathrm{~h}$ and (b) the selected area electron diffraction pattern from the center area. $\theta$-phase structure was retained. Beam $/ /[010]_{\theta}$.

der was heated and observed by TEM to investigate its microstructural stability. The results are summarized as the following:

(1) Spherical $\gamma-\mathrm{Al}_{2} \mathrm{O}_{3}$ particles containing 4 at $\% \mathrm{Mg}$ were prepared by burning a metal $\mathrm{Al}$ block on an alumina brick containing $\mathrm{MgO}$ in a burner in air.

(2) The prepared powder was heated at $1400^{\circ} \mathrm{C}$ for 6 $h$ in a vacuum. The $\gamma$-phase structure was still maintained and sintering was greatly restrained.

(3) After heating at $1500^{\circ} \mathrm{C}$ for $120 \mathrm{~h}$, the powder was sintered and the particle size increased, however, the structure was still $\gamma$-phase.

(4) From the results of HREM, electron diffraction patterns and EDS, it is considered that $\mathrm{Mg}$ atoms effectively stabilize the fundamental structure of $\gamma-\mathrm{Al}_{2} \mathrm{O}_{3}$, spinel, crystallographically.

\section{Acknowledgment}

We thank Mr. Tsukasa Hirayama of JFCC for providing a sample and useful suggestions.

\section{REFERENCES}

(1) A. Kato, H. Yamashita, H. Kawagoshi and S. Matsuda: J. Am. Ceram. Soc., 70 (1987), C-157.

(2) S. Matsuda, A. Kato, M. Mizumoto and H. Yamashita: Proc. of 8th International Congress on Catalysis, Vol. 4, Berlin, (1984), p. 879.

(3) T. Hirayama: J. Am. Ceram. Soc., 70 (1987), C122.

(4) T. Hirayama: Yogyo-Kyokai-shi, 95 (1987), 253

(5) S. Iijima: Jpn. J. Appl. Phys., 23 (1984), L347.

(6) J. E. Bonevich and L.D. Marks: J. Mater. Res., 7 (1992), 1489. 